\section{Answering questions about the White House Conference}

\author{
by Patricia A. Wand
}

Chair, ACRL Task Force on WHCLIS

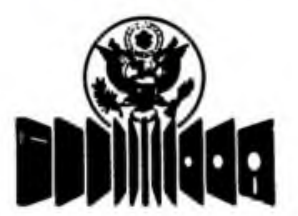

THE WHITE HOUSE CONFERENCE ON
LIBRARY AND INFORMATION SERVICES
1991
- Did the White House Conference on Library and Information Services II (WHCLIS) actually take place at the White House?

No, WHCLIS was held July 9-13, 1991, at the Washington Convention Center about 8 blocks from the White House. It was named the "White House" conference because it focused on federal roles in relation to information centers and on setting a national information agenda for the decade.

\section{- How would you describe WHCLIS?}

The White House Conference was unlike any conference I have ever attended. It was more of a congress than a conference in that the status of attendees played an important role and lent a special environment. Because the time frame was tight and the agenda long, the intense task-orientation created a level of stress not usually found in conferences. WHCLIS was smaller than conferences of the ALA. It was conducted along strictly enforced protocols with written rules for debate and decision-making. Anyone could have registered as an observer but the real work was carried out by delegates. Delegates were pre-selected and represented various geographic regions and constituents. Their work focused on issues that had been framed during the 60 or so pre-White House Conference events. The charge to delegates was to formulate resolutions and an agenda for the federal role in the next decade of the information age.

- How was the White House Conference structured?

The schedule included the Presidential address, a speech by the First Lady, conference briefings and official greetings, theme and keynote speakers, receptions, meal events, discussions in small and large groups, a Joint Congressional Hearing, and the Great Debate on the future of information service. Key people throughout the Conference were: Charles Reid, chairman, White House Con- ference; Richard Akeroyd, chairman, White House Advisory Committee; Joseph Fitzsimmons, vice chairman, White House Conference; Jean Curtis, executive director, White House Conference; Peter Young, executive director, National Commission on Libraries and Information Science; Phillip Blumberg, presidingofficer; Jane Klausman, chief parliamentarian.

During the all-conference events in the main hall, there was a strictly enforced, hierarchical seating arrangement with sections clearly marked as follows: speakers platform; delegates, seated in groups by state; delegates-at-large; honorary and alternate delegates (no speaking or voting privileges); observers-official and self-sponsored; and volunteers. Microphones were available only in the delegates section and security guards checked badges for the appropriate color-code before allowing anyone to enter that area.

- Were the concerns of academic libraries addressed?

Definitely yes, academic library issues were discussed and covered in WHCLIS. The original 130 draft resolutions were prioritized by delegates and of the top 25 resolutions, 19 are directly related to academic libraries. Topics of those top 19 are:

-information superhighway modeled on proposed National Research and Education Network

- funding for libraries

- marketing library services

- preservation policy and needs assessment

- recognition of libraries in federal government structure, including congressional committees on libraries and higher status in the Department of Education

- meeting information needs of multi-cultural, multi-lingual populations

- revisions in copyright legislation

-access to government information, including non-exempt government-sponsored research

-protecting rights of intellectual freedom 
-assuring confidentiality and protecting against censorship

-including libraries in America 2000:An Education Strategy (Washington, D.C.: U.S. Department of Education, 1991) [Ed. note: See the Congressional Record, July 11, 1991, vol. 137, no. 106 for a discussion of this document in Major Owens's address, "Libraries in America 2000."

-increased funding for collection development

-reduced rates for mail and telecommunications

-eliminate physical barriers in information centers

-recruiting for the information profession and scholarships for minorities.

\section{- Who were delegates?}

In all there were 636 delegates and 48 delegatesat-large. They came in all shapes, sizes, and colors; they spoke many languages; they had various physical abilities. In short, they represented a broad cross-section of the population. In terms of their relationship to libraries, one-fourth of the delegates were information professionals, one-fourth were trustees and friends of libraries, one-fourth were govermment officials or employees, and one-fourth were users of libraries and information services. Delegates had voting rights and could speak during plenary sessions and topic group discussions. Resolutions were drafted by delegates in 30 subgroups focusing on 10 different topics. Delegates-at-large were invited to serve in that capacity because of their positions in the world of information storage and service or because their expertise was missing among the delegates and was needed to provide a well-rounded group perspective. Delegates-at-large enjoyed the same privileges as delegates.

\section{- Who were others attending the White House Conference?}

In all over 1,600 people attended WHCLIS, 1,000 of whom were honorary delegates, alternate delegates, observers, and volunteers. Honorary delegates were invited because of their roles in the profession or their participation in pre-White House Conference events and planning. They were allowed to speak during topic group discussions but could not vote or speak during plenary sessions. Alternate delegates had the same privileges as honorary delegates and became delegates if delegates from their states or territories were unable to serve. Observers paid a registration fee and could attend all plenary sessions and various special events. They could observe topic group discussions if there was space. Volunteers played a vital role in the Conference by serving as facilitators, moderators, recorders, computer operators, couriers, and hosts.

- You have discussed many positive aspects of the White House Conference. Was there anything you did not like about the Conference?

Yes, there was. I did not like having to keep quiet during discussions. As an honorary delegate, I was permitted to participate only in discussions of small topic groups and only if the facilitator recognized me. Since most delegates were as eager to talk as I was, I seldom had the opportunity to contribute. It was frustrating! I must add that, given the number of delegates and the need to draft resolutions in a short time frame, I understand the rationale behind the strictly-enforced protocol.

\section{- Some delegates reported observing little mass media coverage of WHCLIS. What in fact was the media coverage?}

Although there was little printed in the Washington Post during the White House Conference itself, there was considerable coverage throughout the U.S. A number of national newspapers, including The New York Times, USA Today, Christian Science Monitor, and Chronicle of Higher Education, carried stories. News of the event appeared in at least 32 regional and local newspapers. Among these were Chicago Sun Times, The Los Angeles Times, Cincinnati Enquirer, Baltimore Sun, and The Miami Herald. Perhaps the widest coverage was via radio broadcasts. Crosstalk, a 30 -minute CBS discussion show, interviewed Peter Young, director, National Commission on Libraries and Information Science, and Richard Akeroyd, WHCLIS co-chairman, about the event. $A B C$ World News Tonight covered WHCLIS within a story on library funding issues. Interviews with delegates and members of the WHCLIS Advisory Committee were taped for radio airing during the conference and broadcast in major media markets by more than 55 different stations across the country. Staff at the Office of the White House Conference aimed press releases and press conferences at hometown and trade publications. In this case "trade" is considered the library and information service profession. Coverage in those publications was considerable. More than 22 publications carried detailed stories and/or covered the event for their readership.

\section{- What will you remember most about WHCLIS?}

On opening day we heard Barbara Bush before lunch, Marilyn Quayle during lunch, and George Bush after lunch. How can one forget a menu like that? Putting aside all political preferences, everyone takes note when the President of the United States addresses an assembly. The content of their speeches indicated awareness of the importance of libraries and information services. Each of the three highlighted different aspects of the role of libraries but the bottom line was that libraries and access to 

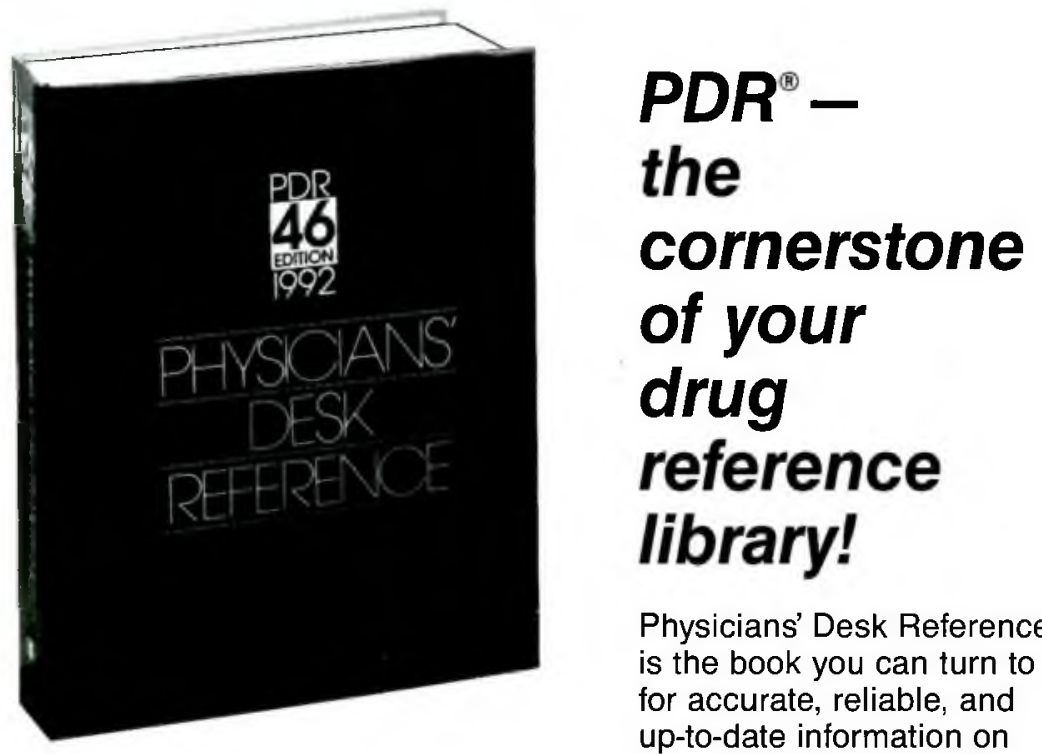

Physicians' Desk Reference ${ }^{\circledR}$ is the book you can turn to for accurate, reliable, and up-to-date information on prescription drugs.

Easy to use and quick to scan, the all-new 1992 Edition contains vital information listed by product name, category, manufacturer, and chemical and generic names.

The 1992 PDR gives you official FDA labeling information on virtually all prescription drugs. Product descriptions provided by the manufacturers have been edited and approved by their individual medical departments.

It's this attention to detail and research that has earned the respect of everyone who has relied on it since 1947; and made PDR The Source for prescription drug data.

- Published January 1992

- ISBN: 1-56363-003-6

- $\$ 54.95$

To order, contact your library wholesaler.

For more information, write: Physicians' Desk Reference, 5 Paragon Drive, Montvale, NJ 07645. Phone: 201-358-7200 FAX: 201-573-4956 
information are vital to a democracy, to human development and to a healthy economy.

George Bush acknowledged the importance of libraries in education and research and recognized their changing nature due to technological advances. Consistent with her life-long commitment, Barbara Bush focused on the role of libraries in promoting and assuring literacy of family members without regard to age.

Marilyn Quayle talked about the vital role of the library in the community, in strong liberal arts education, and in the development of the whole person. She drew heavily on writers who have contributed through literature and history to the advancement of culture. She came back to the importance of the archival role of libraries.

Being graced with the support and presence of George Bush, Barbara Bush, and Marilyn Quayle lent credence to the Conference's White House connection! If it is true that people are judged by the company they keep, then it is safe to say that library users, librarians, and information professionals are a very distinguished group!

\section{- Who were other speakers?}

To name some of the featured speakers: Lamar Alexander, Secretary of Education; James Billington, Librarian of Congress; William Esrey, president and CEO, US Sprint; J. Michael Farrell, partner in Manatt, Phelps, \& Phelps law firm; Mary Hatwood Futrell, associatedirector, Center for the Study of Education and National Development, George Washington University; Newt Gingrich, U.S. Representative, Georgia; Janette Hoston Harris, director, Educational Affairs, District of Columbia; Deborah Kaplan,director, Division on Technology Policy, World Institute on Disability; Major Owens, U.S. Representative, New York, and librarian; Paul Simon, U.S. Senator, Illinois.

Participants in the Great Debate regarding the future of library and information services were: Clement Bezold, executive director, Institute for Alternative Futures; Robert Houk, U.S. Public Printer; Charles McClure, professor, School of Information Studies, Syracuse University; Anthony Oettinger, chairman, Program on Information Resources Policy, Center for Information Policy Research, Harvard University; Amy Owen, Utah State Librarian; Charles Robinson, director, Baltimore County Public Library; Jack Simpson, president, Mead Data Central; Phyllis Steckler, president, The Oryx Press; Don Wilson, Archivist of the U.S.

- Do you think the White House Conference will make a difference?

The difference it makes depends on us. The agenda has been set, the resolutions are written. The responsibility to implement the program lies with the profession and with Congress. Congress responds to pressure. You and I make up the profession. If we want to achieve the goals we set, we must apply pressure to Congress and work toward the goals systmatically.

\section{- How can ACRL members help achieve the goals?}

If each of us does a little collectively we can make a difference. Here are a few suggestions:

- Read the final 100 resolutions of WHCLIS. All delegates received copies and additional copies are available on a limited basis from the Office of WHCLIS. Call 1-800-WHCLIS2 and inquire.

- Contact delegates who represented your state or territory. Invite them to a meeting of your ACRL Chapter to discuss WHCLIS and the resolutions. Ask them how you and your colleagues can help achieve the goals.

- Talk with colleagues in your ACRL Chapter about activities that can be carried out on the local level.

-Implement the Legislative Network as proposed by the ACRL Government Relations Committee and use it to help articulate library needs to your representatives in local, state, and federal governments.

- Learn about library issues that affect your community and state. Get involved in addressing the issues through local political processes.

\section{Rare book cataloging report published}

Rare Book Cataloguing in the British Isles, by Ann Lennon and David Pearson, a report based on data collected from a survey of libraries, has been published by the British Library. The authors surveyed 183 libraries of all types to gather information on current practice in rare book cataloging around the British Isles, with particular emphasis on the descriptive codes in use and the impact of automation.

The survey found that there is considerable diversity of practice in rare book cataloging in the British Isles, both in the codes used and the elements of information recorded. It also found widespread dissatisfaction with the UKMARC format as presently defined, because it fails to provide fields for many of the specialized elements essential to rare book work.

Copies of the 53-page report are $£ 10.00$ (ISBN 0712332537 ) and may be ordered from: British Library Publications Sales Unit, Boston Spa, Wetherby, West Yorkshire LS237BQ, UK 